\title{
Exploring Author Visibility in Academic Writing in EFL Tanzanian Context: A Case Study of University of Dar es Salaam Postgraduate Dissertations and Theses
}

\author{
Erasmus Akiley Msuya \\ University of Dar es Salaam, College of Humanities \\ Department of Foreign Languages and Linguistics. Tanzania
}

\begin{abstract}
This study analyzed mode and extent of author visibility in Academic writing in EFL context. The study was guided by Hyland's (2005) metadiscourse model and it was conducted in the University of Dar es Salaam and involved twenty seven postgraduate theses and dissertations from the University main library. The areas in focus were on abstract, acknowledgement, declaration, statement of the problem, aim and objectives, significance of the study, literature review, theoretical framework, methodology, data presentation and analysis, conclusions and recommendations. To each part frequencies of occurrences were sought of self-mention or lack thereof and discourse functions of the self-mention were probed. The findings revealed that University of Dar es Salaam EFL academic writers, in their adherence to norms and conventions of academic writing, tended to be extremely formal, favouring invisibility over visibility by their less use of first person (singular or plural) and more use of third person.
\end{abstract}

Keywords: EFL, Authorial Visibility, Self-mention, Discourse Function

\section{INTRODUCTION}

Among the norms that characterise academic writing is the formal style calling as much as possible the detachment of the writer both in their emotional involvement and their explicit self-mention. Scholars, like Tannen (1982: 3, cited in Petch-Tyson1998: 107), posit that the degree to which interpersonal involvement or message content carries the signalling load helps distinguish between spoken and written language, in which the interpersonal involvement carries the signalling load in spoken language, whereas message content carries the load in written language. The latter pays special attention in impersonality, which is seen as a defining feature of expository writing as it embodies the positivist assumption that academic research is purely empirical and objective. Geertz (1988) refers to this as "author-evacuated" prose, and many textbooks and style guides advise students to avoid personal intervention.

This outlooks is regarded as purely empirical and objective. Therefore, it was seen as related to "clarity, economy, rational argument supported by evidence, caution and restraint" (Bennett, 2009: 52) and best presented as if human agency was not part of the process (Hyland, 2001). Hyland (1999) notes that academic writing courses and style manuals typically advise beginner writers to avoid the use of personal forms and to opt for passive voice, abstract rhetoric and other impersonal constructions.

Hyland (2002) cites the following proscriptions from some scholars in this field:

- To the scientist it is unimportant who observed the chemical reaction: only the observation itself is vital. Thus the active voice sentence is inappropriate. In this situation, passive voice and the omission of the agent of action are justified (Gong and Dragga, 1995).

- Write your paper with a third person voice that avoids 'I believe' or 'It is my opinion' (Lester, 1993: 144).

- The total paper is considered to be the work of the writer. You don't have to say 'I think' or 'My opinion is' in the paper. (. . .) Traditional formal writing does not use 'I' or 'we' in the body of the paper (Spencer and Arbon, 1996: 26). 
- In general, academic writing aims at being 'objective' in its expression of ideas, and thus tries to avoid specific reference to personal opinions. Your academic writing should imitate this style by eliminating first person pronouns ... as far as possible (Arnaudet and Barrett, 1984: 73).

Thus, students have to develop the "peculiar ways of knowing, selecting, evaluating, reporting, concluding and arguing that define the discourse of the community" (Bartholomae, 1986: 4). They must write with authority, and to do this they must use another's voice and another's code, weakening their affiliations to their home culture and discourses to adopt the values and language of their disciplinary ones (Johns, 1997: 64).

However, arguments for author visibility are increasingly becoming popular. Again, Hyland (Ibid.) cites a few scholars in this camp:

- I herewith ask all young scientists to renounce the false modesty of previous generations of scientists. Do not be afraid to name the agent of the action in a sentence, even when it is 'I' or 'we' (Day, 1994: 166).

- ... .most of our recommendations are designed to help you maintain a scholarly and objective tone in your writing. This does not mean (and we have not said) that you should never use I or we in your writing. The use of 'I' or 'we' does not make a piece of writing informal (Swales and Feak, 1994: 20).

- .....the scientific attitude is not achieved by either the use or the avoidance of a particular pronoun. Rather, it is achieved through the qualities mentioned earlier: honesty, care in handling facts, dignity, and restraint in manner (Mills and Water, 1986: 32-33).

This second part is of interest to this study, seeking to establish the extent of authorial presence. This presence is contextual used to refer to the degree of visibility and authoritativeness writers are prepared to project in their texts for personal support of their statements when expressing their attitudes, judgements and assessments (Dontcheva-Navrátilová, 2013).

Generally, scholars concur that the rhetorical and linguistic choices which writers have at their disposal perform two major functions: The first is stance, which is conveyed by the marked or disguised involvement of the author in the argument, and, secondly, engagement, which is associated with the alignment of the writer with the readers, who may be included as participants in the discourse and guided towards intended interpretations (Hyland, 2005). Both aspects of authorial presence help the writers to create a dialogic space for the negotiation of their views by constructing a coherent argument and by providing cohesive clues for the readers in discourse processing.

A number of empirical studies have been carried been carried out in this area. Dontcheva-Navrátilová (2013) focussed on use of author-reference pronouns for the construal of authorial presence in the genre of research articles in the field of linguistics. Petch-Tyson (1998), on his part, explored the degree of writer/reader visibility in argument essays written by four different L1 learner groups as well as native English-speaking university students. He focused on the presence of features signalling writer/reader visibility most accessible by computer software, including first and second personal pronouns and references to the situation of writing or reading. He noted that there was tendency for academic essays written by even advanced, university level English learners to resemble talk written down. The learners were found to have overused first and second person pronouns in their writing.

Cobb's (2000) study on English essays written by Quebec French learners focused on first and second person pronouns in a corpus of English essays written by Quebec French learners and found that they make up 6.47 per cent of the words in the corpus.

Hyland (1999) posited that researchers in both the hard and social science disciplines tend to make use of personal pronouns for three main purposes: to organize their arguments and essays, to discuss their research activities, and to show their position towards conclusions and theoretical viewpoints. Two years later, Hyland (2001) also examined 240 research articles from eight disciplines. He noted that self-mention was emerging a common feature in academic writing enabling the authors to present what he called "an authorial self firmly established in the norms of the discipline and reflecting appropriate degree of confidence and authority" (2001: 216).

Harwood (2005) focused on the self-promotional function of the personal pronouns $I$ and we in published academic writing, using ten articles from leading journals representing four different disciplines. He found that personal pronouns served a number of purposes but that, ultimately, they served as way for the authors to promote themselves. 
Tang and John (1999) examined the use of first person pronouns in 1,000-word academic essays written by 27 first year Singaporean university students. The authors noted that the students employed first person pronouns 92 times in the 27 essays, though a single student's essay accounted for 16 of the pronouns. The most common roles for pronouns were we or $u s$ as a label for a larger group of people.

According to Ivanic' (1998), there are three aspects of identity interacting in writing which she calls the autobiographical self' influenced by the writer's life-history, the discoursal self, the image or 'voice' the writer projects in a text, and the authorial self, manifested in the extent to which a writer intrudes into a text and claims responsibility for its content. It is this third element of identity which I am concerned with in this paper, exploring the degree of authoritativeness writers are prepared to invest in their texts to personally get behind their statements.

This authorial self is largely achieved through a range of rhetorical and linguistic resources, which is variously referred to as appraisal (Martin, 2000), evaluation (Hunston and Thompson, 2000), and stance (Hyland, 1999), which allow writers to take up positions and express judgments. Such strategies convey a range of cognitive and affective meanings and in so doing explicitly announce the writer and negotiate a rhetorical identity. One of the most obvious and important ways writers can represent themselves to readers however is to explicitly affirm their role in the discourse through first person pronouns (Hyland, 2001; Kuo, 1999, Tang and John, 1999). These writers point to the use of 'I' as critical to meaning and credibility, helping to establish the commitment of writers to their words and setting up a relationship with their readers. An empirical example of this is a study by Munoz's (2013) study of the discourse functions of personal pronouns and verb forms referring to writer and reader interaction in a corpus of 60 research articles in the fields of linguistics, psychology and educational research in English and Spanish, drawing on Tang and John's (1999) taxonomy. He found that both English and Spanish writers made extensive use of pronominal discourse functions.

\section{TheORETICAL FramewORK}

This study was guided by metadiscourse model developed by Hyland (2005). The model includes a series of linguistic resources that are divided into two major categories: interactive and interactional. On the interactive side, metadiscourse signals include: transition markers, frame markers, endophoric markers, evidential and code glosses. On the interactional side, they include: hedges, boosters, attitude markers, self-mention, and engagement markers (reader pronouns, personal asides, shared knowledge, directives and questions).

Hyland (2002) observes that the use of first person allows these writers to emphasize, and to seek agreement for, their own contributions. It leaves readers in no doubt where they stand and how their statements should be interpreted. First person then, is a powerful means by which writers express an identity by asserting their claim to speak as an authority, and this is a key element of successful academic writing.

Hyland (ibid) further observes that self-mention constitutes a central pragmatic feature of academic discourse since it contributes not only to the writer's construction of a text, but also of a rhetorical self. The authorial pronoun is a significant means of promoting a competent scholarly identity and gaining acceptance for one's ideas, and while these students were sensitive to its rhetorical effects, they were reluctant to accept its clear connotations of authority and personal commitment. As a result they significantly underused authorial pronouns and determiners, downplayed their role in the research, and adopted a less clearly independent stance compared with expert writers.

\section{Materials ANd Methods}

The study involved twenty seven postgraduate theses and dissertations, the distribution of which appears in Table 1 below.

Table1. Distribution of Theses and Dissertations under Study

\begin{tabular}{|l|l|l|l|l|}
\hline Level & Humanities \& Social Sciences & Natural Science & Laws & Total \\
\hline PG Diploma & 4 & 0 & 0 & $\mathbf{4}$ \\
\hline Masters & 3 & 3 & 3 & $\mathbf{9}$ \\
\hline PhD & 5 & 4 & 5 & $\mathbf{1 4}$ \\
\hline Total & $\mathbf{1 2}$ & $\mathbf{7}$ & $\mathbf{8}$ & $\mathbf{2 7}$ \\
\hline
\end{tabular}


A guide for analysis was developed in the 12 aspects of thesis/dissertations; namely abstract, acknowledgement, declaration, statement of the problem, statement of aim and objectives, significance of the study, literature review, theoretical framework, methodology, presentation and analysis of the findings, drawing conclusions and providing recommendations. In each guide, frequencies of occurrences were sought of self-mention or lack thereof using "I", "We/Us/our", "The Researcher", "He/She", and "The Study". At the second level, frequencies were sought of discourse functions of the self-mention in the same sections of the dissertations/theses. These functions are: stating goals, stating results, personal interactions and acknowledgement, elaborating an argument, and expressing self-benefits.

\section{Results}

The findings are organized into three sections: authorial presence signals, the uses of such signifiers, and overall sums of discourse functions of self-mention.

\subsection{Authorial Presence Signals}

The differing extent of uses of authorial presence indicators/signals across the dissertations or theses are presented in Table 2 below.

Table2. Use of Authorial Presence Signals

\begin{tabular}{|l|l|l|l|l|l|l|l|l|}
\hline & $\mathbf{1}$ & We/us/our & You & $\begin{array}{l}\text { 3rd } \\
\text { person/It }\end{array}$ & $\begin{array}{l}\text { The } \\
\text { researcher }\end{array}$ & He/she & The study & Total \\
\hline Abstract & 0 & 0 & 0 & 25 & 0 & & 45 & $\mathbf{7 0}$ \\
\hline Acknowledgement & 6 & 0 & 20 & 40 & 2 & & 1 & $\mathbf{8 0}$ \\
\hline Declaration & 3 & 0 & 0 & 0 & 1 & & 0 & $\mathbf{5 0}$ \\
\hline Statement of the Problem & 1 & 4 & 0 & 0 & 1 & & 10 & $\mathbf{5 7}$ \\
\hline Objectives & 0 & 0 & 0 & 0 & 2 & 0 & 48 & $\mathbf{5 0}$ \\
\hline Significance & 0 & 0 & 0 & 0 & 2 & 0 & 42 & 44 \\
\hline Literature review & 0 & 4 & 0 & 0 & 2 & 8 & 10 & $\mathbf{2 4}$ \\
\hline Theoretical Framework & 0 & 7 & 0 & 0 & 4 & 3 & 28 & $\mathbf{4 2}$ \\
\hline Methodology & 0 & 1 & 0 & 3 & 3 & 2 & 49 & $\mathbf{5 8}$ \\
\hline Findings & 1 & 4 & 0 & 0 & 1 & 1 & 43 & $\mathbf{5 0}$ \\
\hline Conclusions & 1 & 3 & 0 & 32 & 7 & & 18 & $\mathbf{6 1}$ \\
\hline Recommendations & 0 & 3 & 0 & & 5 & 0 & 37 & $\mathbf{5 5}$ \\
\hline
\end{tabular}

The data in table 2 above have a lot to tell. First, the most preferred pronoun types used were of impersonal style where the writer is but an aloof observer. He/she comments/summarizes the issues even those that are apparently their own. Notably here are 'the study' the 'researcher' and ' $3{ }^{\text {rd }}$ person' or empty ' it.' Exceptions here are in the aspect of acknowledgement and declaration. Secondly, a few authors chose impersonal style even in aspects that were affective in nature such as acknowledgement where there were uses of 'the study' (1), the 'researcher' (2) and " $2^{\text {nd }}$ person" (1).

Third, in the area of acknowledgement and declaration there is predominant use of first person singular of personal pronouns. This is rightly so since these are the areas where the author is a sine qua non giver of gratitude to certain people as well as sole declarants of the ownership of authenticity, originality and imperfections of the thesis/dissertation.

Fourth, two aspects that would require active visibility of the author are in the statement of study and objectives where the author sets out what they want to achieve and in the methodology, where they state how they will go about conducting the study, have none of $1^{\text {st }}$ person pronouns (singular and plural). An equally important area where the author is supposed to be actively visible is in the statement of the problem; yet there is only a single instance where first person singular pronoun was used and first person plural 'we' was used by four authors. The rest chose the impersonal pronouns/nouns, namely; "third person/"it" (40 times), "the study" (10 times) and "the researcher" (2 times).

Finally, recommendations are essentially a scholarly voice of the author where he/she explicitly becomes the originator of the recommendations. However, in the current study, it was 'the study' (used by 37 authors) that made the recommendation on behalf of the author. Only three became explicit of their authorial source in the recommendations.

Generally, the authors tended to favour detachment and linguistic aloofness in their use of authorial signifiers. 


\subsection{General Use of Authorial Signifiers}

We were interested to find out differing percentages in the use of the nouns/personal pronouns irrespective of which aspect of dissertation. Figure 1 below presents such percentages.

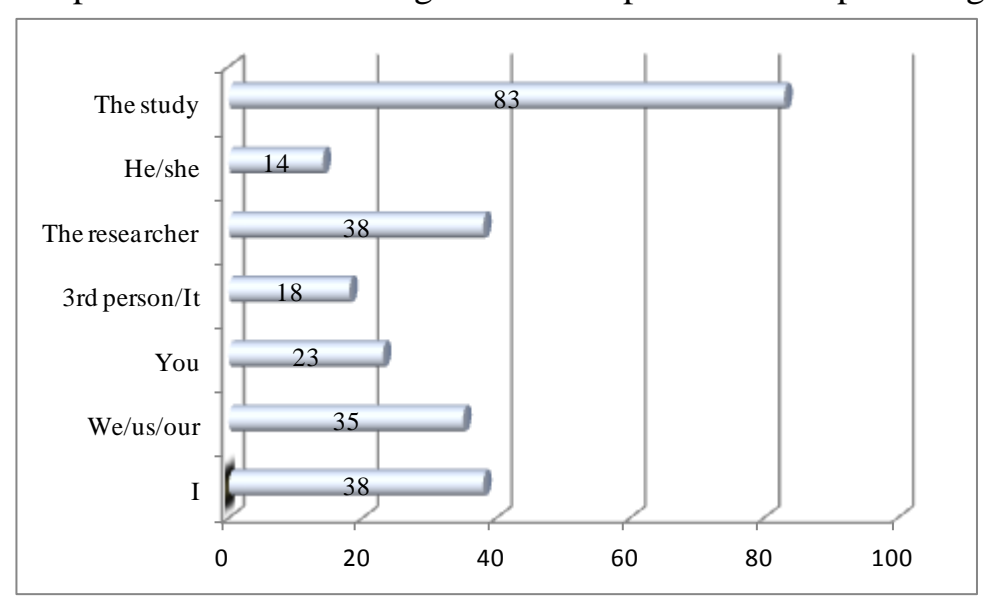

Figure1. The Overall Sums of use Authorial Signifiers (in \%)

The data in Figure 1 above is highly telling of author invisibility and linguistic aloofness as indicated in their use of 'The study' which predominated over all others with $83 \%$ of all usages. This was followed by the researches attributing procedural concerns of the study to the inanimate, abstract being-'the study'. This is the most extreme form of detachment and non-involvement. Ranking second is yet another form of author invisibility - 'the researcher', which has $38 \%$ of occurrences in all theses and dissertations surveyed. This one, unlike the first one, has some kind of author reference even though in a non-committal way with some ambiguity involved in target referent in the sense that 'The researcher' may refer to the writer themselves but also to the author authors cited in the text.

However, there was a fair use of direct author involvement in the use of first person singular ('I'), with $38 \%$ of occurrences, which ranked third, and first person plural ('we'), with $35 \%$, of occurrences, ranking fourth in the popularity of use.

The use of second person (singular and plural), with $23 \%$ of occurrences was only used in areas relating to affectivity (acknowledgement), which is correctly so, given the informal and semi formal allowance warranted by this section of academic writing.

Third person pronominals were the least used with 'it' accounting for $18 \%$ and 'He/She' accounting for $14 \%$. The 'it' usage was that of semantically empty type.

\subsection{Overall Sums of Discourse Function of Self-mention}

We have presented and analyzed author invisibility and visibility in various aspects of dissertation, on the one hard, and in the use of pronouns and specific nouns of the author, on the other. The next stage was our quest for what discourse function the self mention served. Self-mention was either directly in the use of first person singular and plural, i.e. 'I', 'We' and the indirect ones, namely; "the researcher". To achieve this, we listed down the six discourse functions that author self mention serves and we ran SPSS frequencies of the self-mention to establish percentages of occurrence. The resultant data are as summarized in Figure 2.

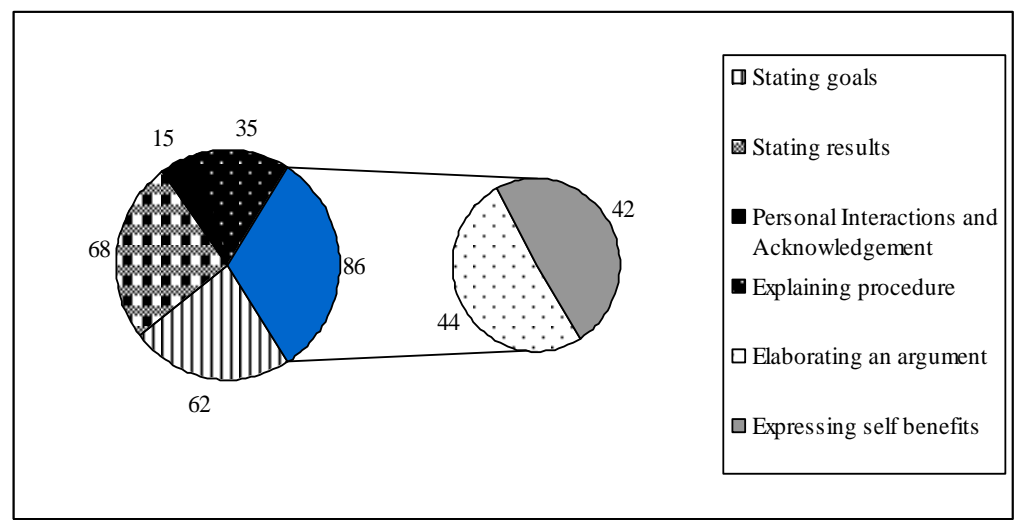

Figure2. Overall sums of Discourse Function of Self-mention 
Facts in figure 2 show the predominance of the discourse function of stating results, with $68 \%$ of occurrence, followed by stating goals, with $62 \%$. These two are dominant given the fact that if the authorial authority is to be most felt, it is in reporting what they sought out to achieve (aim, statement of the problem, and objectives) as well as in presenting their field data (findings and their discussion).

Elaborating an argument in literature review and theoretical framework ranked third, with $44 \%$ and expressing self benefits in the aspects of declarations and significance of the study, ranked fourth with $42 \%$ of occurrences.

The remaining two, which were not as popular, were explaining the procedure (in the aspects of methodology), with $35 \%$, and personal interactions and acknowledgement in the aspect of acknowledgement, with only $15 \%$.

In the same vein, we were interested to find out the discourse function of self-mention (or lack thereof) across parts of dissertations and theses. The results are presented in table 3 below.

Table3. Discourse Functions of Self-mention across Parts of Dissertation/Thesis

\begin{tabular}{|c|c|c|c|c|c|c|}
\hline & $\begin{array}{l}\text { Stating } \\
\text { goals }\end{array}$ & $\begin{array}{l}\text { Stating } \\
\text { Results }\end{array}$ & \begin{tabular}{|l|} 
Personal \\
Interactions and \\
Acknowledgement \\
\end{tabular} & $\begin{array}{l}\text { Explaining } \\
\text { Procedure }\end{array}$ & $\begin{array}{l}\text { Elaborating } \\
\text { an Argument }\end{array}$ & $\begin{array}{l}\text { Expressing } \\
\text { Self - } \\
\text { benefits } \\
\end{array}$ \\
\hline Abstract & 0 & 49 & 1 & 0 & 0 & 0 \\
\hline Acknowledgement & 0 & 0 & 49 & 0 & 0 & 1 \\
\hline Conclusions & 0 & 50 & 0 & 0 & 0 & 0 \\
\hline Declaration & 0 & 0 & 0 & 0 & 0 & 50 \\
\hline Findings & 0 & 50 & 0 & 0 & 0 & 0 \\
\hline Literature review & 0 & 0 & 0 & 23 & 37 & 0 \\
\hline Methodology & 0 & 0 & 0 & 45 & 0 & 5 \\
\hline Objectives & 50 & 0 & 0 & 0 & 0 & 0 \\
\hline Recommendations & 0 & 42 & 0 & 0 & 4 & 4 \\
\hline Significance & 1 & 0 & 0 & 0 & 9 & 40 \\
\hline Statement of the problem & 40 & 0 & 0 & 0 & 10 & 0 \\
\hline Theoretical Framework & 0 & 0 & 0 & 8 & 42 & 0 \\
\hline
\end{tabular}

Table 3 shows that there is one highly dominant discourse function per aspect of dissertation/thesis. Stating results was recurringly dominant in the aspects of abstract (49), conclusions (50), findings (50), and recommendations (42). Expressing self benefits was dominant in declaration (50), and stating significance of the study (40). Stating goals predominated in the statement of objectives (50), and statement of the problem (40).

Personal interactions and acknowledgement is virtually singly dominant in the acknowledgement aspect (50). Explaining procedures predominated in methodology section (45) and literature review (23).

As for distribution of the parts of the dissertation/thesis examined, literature review had two discovery functions, namely; explaining procedure (23) and elaborating an argument (37). In methodology, apart from the discourse function of explaining procedure (45) there was also expressing self-benefits. The recommendations aspect had three discourse functions: stating results (42), elaborating an argument (4), and expressing self-benefits (4), whereas stating the significance of the study had discourse functions of expressing self-benefits (40), elaborating an argument (9), and stating goals.

As for statement of the problem, stating goals predominated with 40 occurrences of self mention, but also had 10 occurrences, of the same serving the function of elaborating an argument. Finally, theoretical framework had two discourse functions of self-mention: elaborating an argument (42) and explaining procedure $(08)$.

\section{Conclusion}

The findings have shown that EFL academic writers, in their adherence to norms and conventions of academic writing, tend to be extremely formal, favouring invisibility. In so doing, the content or subject matter is in the limelight. They subscribe to Gong and Dragga's (1995) exhortations on avoiding agency of the action and favouring passive over active voice. They also adhere to the academic traditionism as propounded by Spencer and Arbon (1996), in which explicit self-mention in the use of first person pronoun is seen as counter-norm. Some writers in this study went to the extreme of self-mention even in acknowledgement sections where the scholars thank and appreciate contributions of some people in making their dissertation/theses production a success. 
However, this work was not on error analysis and, therefore, the observations made refer only to preference of specific norms of academic writing over the others, not just by themselves but also by their supervisors or advisors. This is because dissertations or theses production processes by the candidate operate under close guidance and supervision of a supervisor.

\section{REFERENCES}

Arnaudet, M. and M. Barrett 1984. Approaches to Academic Reading and Writing. Prentice Hall, Englewood Cliffs, NJ.

Bartholomae, D. 1986. "Inventing the University". Journal of Basic Writing 5: 4-23.

Bennett, K. 2009. "English Academic Style Manuals: A Survey". Journal of English for Academic Purposes 8: 43-54.

Cobb, T. 2003. "Analyzing later Interlanguage with Learner Corpora: Quebec Replications of Three European Studies". Canadian Modern Language Review 59 (3) : 393-423.

Day, R. 1994. How to Write and Publish a Scientific Paper. Phoenix: Oryx Press.

Dontcheva-Navrátilová, O. 2013. "Authorial Presence in Academic Discourse: Functions of Authorreference Pronouns". Linguistica Progensia, 1:9-30.

Geertz, C. 1988. Words and Lives: The Anthropologist as Author. Palo Alto, CA: Stanford University Press.

Gong, G. and S. Dragga 1995. A Writer's Repertoire. New York: Longman.

Harwood, N. 2005. " 'Nowhere has Anyone Attempted... In this article I am to do just that': A Corpus-based Study of Self-promotional $I$ and we in Academic Writing Across Four Disciplines". Journal of Pragmatics 37: 1207- 1231.

Hunston, S. and G. Thompson 2000. Evaluation in Text. Oxford: OUP.

Hyland, K. 2005. Metadiscourse: Exploring Interaction in writing. London: Continum.

2002. "Authority and Invisibility: Authorial Identity in Academic Writing". Journal of Pragmatics 34: 1091-1112

2001 . "Humble Servants of the Discipline? Self-mention in Research Articles". English for Specific Purposes 20 (3): 207-226.

1999. "Disciplinary Discourses: Writer Stance in Research Articles". In: Candlin, C., Hyland, K. (eds.), Writing: Texts, Processes and Practices. pp. 99-121. London: Longman.

Ivanič, R. 1998. Writing and Identity: The Discoursal Construction of Identity in Academic Writing. Amsterdam: John Benjamins.

Johns, A. 1997. Text, Role and Context. Cambridge: CUP.

Kuo, C. 1999. "The Use of Personal Pronouns: Role Relationships in Scientific Journal Articles". English for Specific Purposes 18 (2): 121-138.

Lester, J. D. 1993. Writing Research Papers. 7th ed. New York: Harper Collins.

Martin, J. R. 2000. “Analysing Genre: Functional Parameters”. In: Christie, F., and J.R. Martin (eds.), Genre and Institutions. London: Continuum.

Mills, G. and J. A. Water 1986. Technical Writing, 5th ed. Fort Worth, TX: Harcourt Brace Jovanovich.

Munoz, M.C. 2013. "The "I" in Interaction: Authorial Presence in Academic Writing". Revista de Lingüísticay Lenguas Aplicadas 8: 49-58.

Petch-Tyson, S. 1998. "Writer/Reader Visibility in EFL Written Discourse". In S. Granger (ed.). Learner English on Computer, pp. 107-118. London and New York: Longman.

Petch-Tyson, S. 1998. "Writer/Reader Visibility in EFL Written Discourse". In S. Granger (ed.). Learner English on Computer, 107-118. New York: Longman.

Spencer, C. and B. Arbon 1996. Foundations of Writing: Developing Research and Academic Writing Skills. Lincolnwood, IL: National Textbook Co.

Swales, J. and C. Feak 1994. Academic Writing for Graduate Students: Essential Tasks and Skills. University of Michigan Press, Ann Arbor, MI.

Tang, R. and S. John 1999. "The 'I' in Identity: Exploring Writer Identity in Student Academic Writing through the First Person Pronoun”. English for Specific Purposes 18, $23-39$. 